Universidad de Lima

Facultad de Derecho

Carrera de Derecho

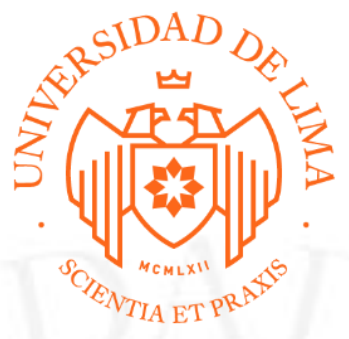

\title{
ARBITRAJE: "ARBITRAJE AD HOC EN LAS CONTRATACIONES CON EL ESTADO" Y ADMINISTRATIVO: "ADMINISTRATIVO SANCIONADOR"
}

Trabajo de suficiencia profesional para optar el Título Profesional de Abogado

\author{
Mariela Paz Malpartida Vidal
}

Código 20081540

Lima - Perú 


\section{ARBITRAJE: "ARBITRAJE AD HOC EN LAS CONTRATACIONES CON EL ESTADO"}

Materia: Arbitraje en Contrataciones con el Estado

$\mathrm{N}^{\circ}$ de Expediente: Sin Número

\section{RESUMEN}

El presente expediente comprende la demanda de nulidad de resolución de contrato interpuesto por A. A. A. S.A.C. - B. B. S.A. contra la Contraloría General De La República, en donde el Tribunal Arbitral determinará si el demandante incurrió en la causal de resolución del contrato, esto es el haber acumulado el monto máximo establecido para penalidades por el concepto de "otras infracciones susceptibles de penalidades y sanciones establecidas en las Bases Integradas".

\section{REGISTRAL: ADMINISTRATIVO: "ADMINISTRATIVO SANCIONADOR"}

Materia: Derecho Administrativo Sancionador

$\mathrm{N}^{\circ}$ de Expediente: $2474-2017 . \mathrm{TC}$

\section{RESUMEN}

El presente expediente comprende la denuncia interpuesta por el Instituto Nacional de Defensa de la Competencia y de la Protección de la Propiedad Intelectual - INDECOPI contra C. C. C. S.A.C. - D. D. S.A.C., en donde la Tercera Sala del Tribunal de Contrataciones del Estado determinará si el denunciado ha incurrido en la infracción establecida en el inc. j) numeral 51.1 de la Ley, esto por haber presentado supuestos documentos falsos o información inexacta. 